\title{
Effect of curing mode on the hardness of dual-cured composite resin core build-up materials
}

\author{
César Augusto Galvão Arrais ${ }^{(a)}$ \\ Aline De Cerqueira Kasaz(b) \\ Luís Gustavo Barrote Albino(c) \\ José Augusto Rodrigues(a) \\ Andre Figueiredo Reis ${ }^{(a)}$
}

(a) DDS, MSc, PhD, Assistant Professor; (b)DDS, MSc student; (c) DDS, MSc, Adjunct Professor - Department of Operative Dentistry, School of Dentistry, University of Guarulhos, SP, Brazil.
Corresponding author:

José Augusto Rodrigues

R. Dr. Nilo Peçanha, 81, Prédio U, $6^{\circ}$ Andar, Centro

Guarulhos - SP - Brazil

CEP: 0701 1-040

Email:gutojar@yahoo.com.br

Received for publication on Apr 07, 2009 Accepted for publication on Sep 08, 2009

\begin{abstract}
This study evaluated the Knoop Hardness (KHN) values of two dual-cured composite resin core build-up materials and one resin cement exposed to different curing conditions. Two dual-cured core buildup composite resins (LuxaCore ${ }^{\circledR}$-Dual, DMG; and FluoroCore ${ }^{\circledR} 2$, Dentsply Caulk), and one dual-cured resin cement (Rely X ARC, 3M ESPE) were used in the present study. The composite materials were placed into a cylindrical matrix ( $2 \mathrm{~mm}$ in height and $3 \mathrm{~mm}$ in diameter), and the specimens thus produced were either light-activated for $40 \mathrm{~s}$ (Optilux 501, Demetron Kerr) or were allowed to self-cure for $10 \mathrm{~min}$ in the dark $(\mathrm{n}=5)$. All specimens were then stored in humidity at $37^{\circ} \mathrm{C}$ for $24 \mathrm{~h}$ in the dark and were subjected to KHN analysis. The results were submitted to 2way ANOVA and Tukey's post-hoc test at a pre-set alpha of 5\%. All the light-activated groups exhibited higher KHN values than the self-cured ones $(\mathrm{p}=0.00001)$, regardless of product. Among the self-cured groups, both composite resin core build-up materials showed higher KHN values than the dual-cured resin cement $(\mathrm{p}=0.00001)$. LuxaCore ${ }^{\circledR}$-Dual exhibited higher KHN values than FluoroCore ${ }^{\circledR} 2(\mathrm{p}=0.00001)$ when they were allowed to self-cure, while no significant differences in $\mathrm{KHN}$ values were observed among the light-activated products. The results suggest that dual-cured composite resin core build-up materials may be more reliable than dual-cured resin cements when curing light is not available.
\end{abstract}

Descriptors: Post and core technique; Resin cements; Composite resins; Hardness.

\section{Introduction}

Core build-up materials are often required to provide an ideal anatomic form to severely damaged teeth prior to their preparation for indirect restorations. Several materials have been indicated for this purpose, but composite resin core build-up materials have been widely used lately. ${ }^{1}$ An ideal restoration is not the final goal and time limitations when placing core build-ups do not usually allow clinicians to use multi-layering techniques. Therefore, dual-cured resin composites for core build-up have been developed. The use of these resinous materials allows clinicians to build the damaged tooth using thick resin layers, as self-curing components may assure proper polymerization even when the curing light is severely attenuated by resin shade. ${ }^{2,3}$

Recently, dual-cured resin composites for core build-up have also been 
used to cement pre-fabricated posts into flared root canals, where a thick resin cement layer would normally be present between the post and root walls. However, an excessively thick cement layer in that region ${ }^{4}$ may not provide proper mechanical properties to withstand occlusal loading, as previously demonstrated by D'Arcangelo et al. ${ }^{5}$ (2007). Thus, considering that the maximum shear stress is primarily located at the post/cement/dentin interface, ${ }^{6}$ a luting material with improved mechanical properties could resist occlusal loading, and other stresses generated by chewing forces, better than dual-cured resin cements. Moreover, dual-cure composite resin core build-up materials may be more appropriate for cementing pre-fabricated posts into root canals as they supposedly have better mechanical properties than dual-cured resin cements.

Studies have evaluated the bond strength of posts cemented with resin cements, along with a variety of bonding agents, as well as the bond strength of direct core foundation systems to teeth. ${ }^{7,8}$ Some focused on chemical incompatibility between bonding agents and resin cements, ${ }^{8-12}$ while others emphasized the importance of an adequate polymerization of dual-cured resin cements. ${ }^{13,14}$ The results from most studies have demonstrated that the self-curing mechanism is not as effective as the light-curing one. ${ }^{13-16}$ However, no information is available in the literature regarding monomer conversion of dualcured resin composites used for core foundations when they are deprived of curing light in deep areas, or when they are used to cement posts into root ca- nals. Therefore, the aim of the present study was to evaluate the hardness - which has been considered an indirect assessment of monomer conversion ${ }^{14,17,18}$ - of dual-cure composite resin build-up materials when they are subjected to different curing conditions. The research hypothesis of the present study was that the self-curing mode of these resin composites leads to higher hardness values than those of the resin cement.

\section{Material and Methods}

Two dual-cure core composite resin build-up materials and one dual-cure resin cement were used in the present study: LuxaCore ${ }^{\circledR}$-Dual (DMG, Chemisch Pharmazeutische Fabrik, Hamburg, Germany), FluoroCore ${ }^{\circledR}$ (Dentsply Caulk, Milford, DE, USA), and Rely X ARC (3M ESPE, St. Paul, MN, USA) (Table 1). The resinous materials were manipulated according to the manufacturers' instructions and were placed into a $2-\mathrm{mm}$ high polytetrafluoretylene split mold with an internal diameter of $3 \mathrm{~mm}$. The specimens thus produced were either light-activated (power density: $600 \mathrm{~mW} / \mathrm{cm}^{2}$, Optilux 501; Demetron Kerr, Danbury, CA, USA) for 40 s or were allowed to self-cure for $10 \mathrm{~min}$ in the dark $(\mathrm{n}=5)$ at room temperature. All specimens were then stored in humidity at $37^{\circ} \mathrm{C}$ for $24 \mathrm{~h}$ in the dark.

\section{Microhardness analysis}

The specimens were subjected to Knoop hardness analysis (KHN) (Pantec, Panambra Ind. e Técnica SA, São Paulo, SP, Brazil) using a $25 \mathrm{~g}$ load

\begin{tabular}{|c|c|c|c|}
\hline \multirow{5}{*}{$\begin{array}{r}\text { Table } 1 \text { - Composition of } \\
\text { the dual-cured core build-up } \\
\text { composite resins and resin cement } \\
\text { used in this study (provided by the } \\
\text { manufacturers). }\end{array}$} & \multirow[b]{2}{*}{$\begin{array}{c}\text { Product } \\
\text { (Manufacturer) }\end{array}$} & \\
\hline & & Composition & $\begin{array}{l}\text { Batch } \\
\text { Number }\end{array}$ \\
\hline & $\begin{array}{l}\text { LuxaCore }^{\circledR} \text {-Dual } \\
\text { (DMG) }\end{array}$ & $\begin{array}{l}\text { Preparation of acrylic resin, glass powder and silica. } \\
\text { Contains urethane dimethacrylate, aliphatic dimethacrylate, } \\
\text { aromatic dimethacrylate. }\end{array}$ & 590609 \\
\hline & $\begin{array}{l}\text { FluoroCore }{ }^{\circledR} 2 \\
\text { (Dentsply Caulk) }\end{array}$ & $\begin{array}{l}\text { Base Paste: Barium boron fluoro alumino silicate glass; UDMA. } \\
\text { Catalyst Paste: Barium boron fluoro alumino silicate glass; } \\
\text { UDMA; Aluminum Oxide; Benzoyl peroxide }\end{array}$ & 0705041 \\
\hline & $\begin{array}{l}\text { Rely X ARC } \\
\text { (3M ESPE) }\end{array}$ & $\begin{array}{l}\text { Paste A: Silane-treated silica, TEGDMA, bis-GMA, } \\
\text { functionalized dimethacrylate polymer } \\
\text { Paste B: Silane-treated ceramic, TEGDMA, bis-GMA, silane } \\
\text { treated silica, functionalized dimethacrylate polymer }\end{array}$ & GEHG \\
\hline
\end{tabular}

TEGDMA: triethylene glycol dimethacrylate; bis-GMA: bisphenol A diglycidyl ether methacrylate; UDMA: urethane dimethacrylate. 
with a dwell time of 5 seconds. Five indentations, at $100 \mu \mathrm{m}$ distance from each other, were made to determine the average KHN value for each specimen. The data obtained from the resinous materials were submitted to 2-way ANOVA ("product" and "activation mode" factors) and Tukey's post-hoc test at a pre-set alpha of $5 \%$ using the Sanest statistical package (UNESP, Jaboticabal, SP, Brazil).

\section{Results}

The results are presented in Table 2. All the light-activated groups exhibited higher KHN values than the self-cured ones $(p=0.00001)$, regardless of product. Among the self-cured groups, LuxaCore ${ }^{\circledR}$ Dual exhibited higher KHN values than FluoroCore ${ }^{\circledR 2}(\mathrm{p}=0.00001)$, and both products exhibited higher KHN values than the dual-cured resin cement $(p=0.00001)$. No significant differences in $\mathrm{KHN}$ values were observed among the products when they were light-activated.

\section{Discussion}

The results demonstrated that the self-curing mode was not able to provide KHN values as high as those provided by the light-curing mode, regardless of product. These findings are similar to those reported in the literature for dual-cured resin cements when they were allowed to self-cure. ${ }^{14,19,20}$ However, both dual-cured composite resin core build-up materials showed higher KHN values than the dual-cured resin cement when they were allowed to self-cure, so the research hypothesis of the present study was validated.

The differences in KHN values among products in self-curing mode cannot be attributed solely to

Table 2 - KHN values of the dual-cure core build-up composite resins and resin cement when they were light-activated or allowed to self-cure.

\begin{tabular}{c|c|c}
\hline & Allowed to self-cure & Light-activated \\
\hline LuxaCore $^{\circledR}$-Dual & $42.6(3.7) \mathrm{Aa}$ & $49.2(5.5) \mathrm{Ab}$ \\
\hline FluoroCore $^{\circledR 2}$ & $35.6(5.5) \mathrm{Ba}$ & $44.0(4.5) \mathrm{Ab}$ \\
\hline Rely X ARC & $6.6(1.8) \mathrm{Ca}$ & $44.0(4.1) \mathrm{Ab}$ \\
\hline
\end{tabular}

Group means followed by similar letters (capital letters - column; lowercase letters - row) are not significantly different for $p<0.05$. differences in monomer conversion, as differences in monomer composition and content of filler particles play an important role in the mechanical properties of resin-based materials. ${ }^{21-23}$ According to the manufacturers' information, LuxaCore ${ }^{\circledR}$-Dual presents $72 \%(\mathrm{wt})$ of filler particles in its composition, while FluoroCore ${ }^{\circledR} 2$ and Rely X ARC present a filler content of approximately $65 \%$ and $67.5 \%$ (wt), respectively. Moreover, both LuxaCore ${ }^{\circledR}$-Dual and FluoroCore ${ }^{\circledR} 2$ present UDMA in their composition, while Rely X ARC composition is based on TEGDMA and Bis-GMA monomers. Some studies have demonstrated that UDMA-based composites have increased monomer conversion ${ }^{24}$ and improved mechanical properties in comparison to Bis-GMA/ TEGDMA composites. ${ }^{25-27}$ It is possible that the differences in filler content among materials may have contributed to the differences in KHN values when resin-based materials were allowed to self-cure.

On the other hand, the self-curing mechanism of each product may have also been partly responsible for differences in KHN values among the self-cured groups. According to the manufacturers' information, the setting time of LuxaCore ${ }^{\circledR}$-Dual and FluoroCore ${ }^{\circledR} 2$ ranges from 3 to $5 \mathrm{~min}$ in the self-curing mode. This time differs from that of RelyX ARC, which takes approximately $10 \mathrm{~min}$ to cure. Considering that the setting time in the self-curing mode is mainly related to the amount of self-curing components, it is possible to speculate that products such as LuxaCore ${ }^{\circledR}$-Dual and FluoroCore ${ }^{\circledR} 2$, with shorter setting times, present higher content of self-curing components than RelyX ARC. These assumptions may be confirmed by the differences in KHN values between the light- and self-curing groups within each product. The KHN values of the LuxaCore ${ }^{\circledR}$ Dual and FluoroCore ${ }^{\circledR} 2$ self-curing groups corresponded respectively to $86.6 \%$ and $80.9 \%$ of the values observed in the light-activated groups, while the KHN values observed for the self-curing mode of RelyX ARC corresponded to only $15 \%$ of the values observed in the light-activated group. Therefore, it was possible to note that the self-curing components in the dual-cured composite resin core buildup materials were more effective than those in the dual-cured resin cement. 
Despite the differences in monomer composition and filler content, no significant differences in KHN values were noted among the light-activated groups. These results were unexpected since differences in filler content have been reported to affect hardness considerably. ${ }^{22}$ One possible explanation for this finding may be related to the effectiveness of lightactivation, which rendered proper polymerization and crosslinking formation capable of compensating for the expected differences in mechanical properties among materials because of the differences in product composition.

The self-curing mode provided KHN values in the dual-cured resin cement considerably lower than those reported by other investigations. ${ }^{19,28}$ Some studies have demonstrated that RelyX ARC reaches a low degree of conversion and hardness in the selfcuring mode within $10 \mathrm{~min}$, in comparison to other dual-cured resin cements, ${ }^{13,19}$ but a significant increase in hardness has been observed over time..$^{19,28}$ A possible explanation for the low KHN values observed in the present study even $24 \mathrm{~h}$ after initial polymerization may be related to storage conditions. Considering that low monomer conversion values are observed within 10 min when RelyX ARC was allowed to self-cure, ${ }^{10,13}$ it is possible that the storage of poorly polymerized specimens in humidity resulted in fast water diffusion into the polymer matrix as previously demonstrated in other studies. . $2,29,30^{2}$ As a consequence, the presence of water in the polymer network may have impaired further resin ce-

\section{References}

1. Schwartz RS, Robbins JW. Post placement and restoration of endodontically treated teeth: a literature review. J Endod. 2004;30(5):289-301.

2. Milleding P, Ortengren U, Karlsson S. Ceramic inlay systems: some clinical aspects. J Oral Rehabil. 1995;22(8):571-80.

3. Nathanson D. Etched porcelain restorations for improved esthetics, part II: Onlays. Compendium. 1987;8(2):105-10.

4. Grandini S, Goracci C, Monticelli F, Borracchini A, Ferrari M. SEM evaluation of the cement layer thickness after luting two different posts. J Adhes Dent. 2005;7(3):235-40.

5. D'Arcangelo C, Cinelli M, De Angelis F, D'Amario M. The effect of resin cement film thickness on the pullout strength of a fiber-reinforced post system. J Prosthet Dent. 2007;98(3):1938. ment polymerization, ${ }^{30}$ compromising its mechanical properties. However, further studies involving different storage conditions are required to confirm this speculation.

Based on the findings of the present study, dualcured composite resin core build-up materials might be more reliable for post cementation than the evaluated dual-cured resin cement. However, further studies are required to compare the effectiveness of these products and dual-cured resin cements in bonding posts to root dentin.

\section{Conclusion}

The dual-cured composite resin core build-up materials tested provided improved mechanical properties compared to those of the evaluated dualcured resin cement when all products were allowed to self-cure, so the research hypothesis of the present study was validated. Thus, the use of dual-cured composite resin build-up materials for post cementation may assure reliable mechanical properties even in deep regions where light is not available.

\section{Acknowledgments}

This study was partly supported by The State of São Paulo Research Foundation (FAPESP), grants \# 2004/01175-0, 2007/06083-4 and \# 2007/06447-6. The authors are indebted to Dentsply Caulk, DMG Comp. and 3M ESPE for providing the restorative materials evaluated in the present study.

6. Asmussen E, Peutzfeldt A, Sahafi A. Finite element analysis of stresses in endodontically treated, dowel-restored teeth. J Prosthet Dent. 2005;94(4):321-9.

7. Aksornmuang J, Nakajima M, Foxton RM, Tagami J. Mechanical properties and bond strength of dual-cure resin composites to root canal dentin. Dent Mater. 2007;23(2):226-34.

8. Oooka S, Miyazaki M, Takamizawa T, Tsubota K, Kurokawa $\mathrm{H}$, Rikuta A. Influence of adhesive polymerization mode on dentin bond strength of direct core foundation systems. J Oral Sci. 2004;46(3):185-9.

9. Arrais CA, Giannini M, Rueggeberg FA. Effect of sodium sulfinate salts on the polymerization characteristics of dual-cured resin cement systems exposed to attenuated light-activation. J Dent. 2009;37(3):219-27. 
10. Arrais CA, Rueggeberg FA, Waller JL, de Goes MF, Giannini M. Effect of curing mode on the polymerization characteristics of dual-cured resin cement systems. J Dent. 2008;36(6):41826.

11. Cavalcanti SC, de Oliveira MT, Arrais CA, Giannini M. The effect of the presence and presentation mode of co-initiators on the microtensile bond strength of dual-cured adhesive systems used in indirect restorations. Oper Dent. 2008;33(6):682-9.

12. Hagge MS, Lindemuth JS. Shear bond strength of an autopolymerizing core buildup composite bonded to dentin with 9 dentin adhesive systems. J Prosthet Dent. 2001;86(6):620-3.

13. Arrais CA, Giannini M, Rueggeberg FA. Kinetic analysis of monomer conversion in auto- and dual-polymerizing modes of commercial resin luting cements. J Prosthet Dent. 2009;101(2):128-36.

14. Braga RR, Cesar PF, Gonzaga CC. Mechanical properties of resin cements with different activation modes. J Oral Rehabil. 2002;29(3):257-62.

15. Blackman R, Barghi N, Duke E. Influence of ceramic thickness on the polymerization of light-cured resin cement. J Prosthet Dent. 1990;63(3):295-300.

16. Sigemori RM, Reis AF, Giannini M, Paulillo LA. Curing depth of a resin-modified glass ionomer and two resin-based luting agents. Oper Dent. 2005;30(2):185-9.

17. El-Mowafy OM, Rubo MH. Influence of composite inlay/onlay thickness on hardening of dual-cured resin cements. J Can Dent Assoc. 2000;66(3):147.

18. Ferracane JL. Correlation between hardness and degree of conversion during the setting reaction of unfilled dental restorative resins. Dent Mater. 1985;1(1):11-4.

19. Santos GC Jr., El-Mowafy O, Rubo JH, Santos MJ. Hardening of dual-cure resin cements and a resin composite restorative cured with QTH and LED curing units. J Can Dent Assoc. 2004;70(5):323-8.
20. Fonseca RG, Cruz CA, Adabo GL. The influence of chemical activation on hardness of dual-curing resin cements. Braz Oral Res. 2004;18(3):228-32.

21. Peutzfeldt A. Resin composites in dentistry: the monomer systems. Eur J Oral Sci. 1997;105(2):97-116.

22. Ferracane JL, Berge HX, Condon JR. In vitro aging of dental composites in water - effect of degree of conversion, filler volume, and filler/matrix coupling. J Biomed Mater Res. 1998;42(3):465-72.

23. Rueggeberg FA. From vulcanite to vinyl, a history of resins in restorative dentistry. J Prosthet Dent. 2002;87(4):364-79.

24. Sideridou I, Tserki V, Papanastasiou G. Effect of chemical structure on degree of conversion in light-cured dimethacrylate-based dental resins. Biomaterials. 2002;23(8):1819-29.

25. Asmussen E, Peutzfeldt A. Mechanical properties of heat treated restorative resins for use in the inlay/onlay technique. Scand J Dent Res. 1990;98(6):564-7.

26. Peutzfeldt A, Asmussen E. Ketones in resin composites. Effect of ketone content and monomer composition on selected mechanical properties. Acta Odontol Scand. 1992;50(4):253-8.

27. Peutzfeldt A, Asmussen E. Influence of aldehydes on selected mechanical properties of resin composites. J Dent Res. 1992;71(8):1522-4.

28. Sinhoreti MA, Manetta IP, Tango RN, Iriyama NT, Consani RL, Correr-Sobrinho L. Effect of light-curing methods on resin cement Knoop hardness at different depths. Braz Dent J. 2007;18(4):305-8.

29. Ferracane JL. Hygroscopic and hydrolytic effects in dental polymer networks. Dent Mater. 2006;22(3):211-22.

30. Paul SJ, Leach M, Rueggeberg FA, Pashley DH. Effect of water content on the physical properties of model dentine primer and bonding resins. J Dent. 1999;27(3):209-14. 